\title{
Removal of Ochratoxin A in Saccharomyces cerevisiae Liquid Cultures
}

E. Bizaj ${ }^{1}$, J. Mavri', F. Čuš² and A. Raspor ${ }^{1 *}$

(1) Biotechnical Faculty, University of Ljubljana, Jamnikarjeva 101, 1000, Ljubljana, Slovenia

(2) Agricultural Institute of Slovenia, Hacquetova 17, 1000, Ljubljana, Slovenia

Submitted for publication: August 2009

Accepted for publication: September 2009

Key words: Adsorption, yeast strain, synthetic media, Ochratoxin A, Saccharomyces, alcoholic fermentation

\begin{abstract}
The capacity for removal of ochratoxin A (OTA) during alcoholic fermentation was evaluated in batch systems with one commercial strain and one wild strain of Saccharomyces cerevisiae. Batch alcoholic fermentations were carried out in yeast extract-malt extract broth (YM) medium, with $\mathbf{1 8 . 0 \%}$ glucose and OTA added to final concentrations of 3.48 and $4.95 \mathrm{ng} / \mathrm{mL}$ respectively. The removal capacity of each yeast strain was examined after completion of fermentation in batch culture and after extended contact with yeast biomass. The removal capacity of the yeast strains was also examined in stationary phase cultures. Stationary phase yeasts were studied with biomass harvested from the stationary phase of anaerobic fermentation, by incubation in phosphate buffer, with the addition of $5.00 \mathrm{ng} /$ mL of OTA. Removal studies with stationary phase cells were performed with viable and non-viable cells inactivated with Na-azide. The study showed that in growing phase cultures, OTA removal was significant only after extended contact with yeast biomass; up to $29.7 \%$ and $25.4 \%$ for wild yeast ZIM 1927 and commercial yeast Lalvin EC-1118 respectively, but not during alcoholic fermentation. In stationary phase cultures, viable and non-viable cells were not significantly different in OTA removal from the medium. This demonstrated that OTA was not metabolised, but possibly adsorbed by the yeast cells. The presence of OTA in synthetic media influenced yeast metabolism, causing the production of higher volatile acidity by 0.08 and $0.13 \mathrm{~g} / \mathrm{L}$ for Lalvin EC-1118 and ZIM 1927 respectively, and lower concentrations of reducing sugar, by $0.32 \mathrm{~g} / \mathrm{L}$, but only for ZIM 1927.
\end{abstract}

Ochratoxin A is a strong nephrotoxic, carcinogenic, immunotoxic and teratogenic mycotoxin that can contaminate various foods and beverages, including wines. Its chemical structure consists of a chlorine-containing dihydroisocoumarin linked through the 7-carboxyl group to 1- $\alpha$-phenylalanine (Caridi, 2007).

Ochratoxin A (OTA) is a mycotoxin produced by two genera of fungi, Aspergillus and Penicillium (Mateo et al., 2007). The development of the fungi-producing OTA essentially depends on climatic conditions, and it is found more frequently in regions with temperate and tropical climates (Zimmerli \& Dick, 1996). The black aspergilli that infect grapes and produce OTA are present on berries from the early stages of development, thus an approach to prevent wine contamination involves identifying and controlling these fungi, especially A. carbonarius (Lo Curto et al., 2004; Mateo et al., 2007).

Because of strong toxicity, there is a big concern about the occurrence of ochratoxin A in many commodities, including feeds, foods and beverages (Marquardt \& Frohlich, 1992). Since 1996 , the presence of this toxin has been also reported in grapes and grape products such as grape juice $(<3-311 \mathrm{ng} / \mathrm{L})$ and wine $(<3-388 \mathrm{ng} / \mathrm{L})$ (Zimmerli \& Dick, 1996). The presence of the fungal metabolite OTA in wine therefore represents a serious risk to the consumer's health. In fact, according to some studies, wine is considered the second major source of OTA intake after cereals (Mateo et al., 2007). In this regard, red table wine samples have shown to have higher OTA concentrations than rose and white wine samples, but the highest concentrations have been found in dessert wines (Chulze et al., 2006; Mateo et al., 2007).
The EU has established a maximumallowable OTA concentration of $2 \mathrm{ppb}$ for wines, starting from the vintage of 2005 (EC, 2005), reserving the possibility of lowering this limit following new technological and toxicological research.

In wine production, much OTA is removed in the solidliquid separation stages during pressing in vinification, when the wine or juice is separated from the skins (Leong et al., 2006). It has been reported that 50 to $80 \%$ of the total OTA content originally present in the crushed grapes is bound to the discarded skins and seeds. Various procedures have been developed to remove mycotoxins using yeasts, yeast cell walls or yeast cell wall extracts (Gambuti et al., 2005; Ratola et al., 2005; Caridi, 2007; Fernandes et al., 2007; Hocking et al., 2007). OTA is thought not to be degraded (biologically transformed) by yeasts during primary alcoholic fermentation; rather, the toxin is adsorbed onto yeast mannoproteins, but these vary in their adsorptive capacity. However, there is no firm consensus about the proposed mechanism involved in the removal of OTA (Bejaoui et al., 2004; Caridi, 2006; Cecchini et al., 2006; Hocking et al., 2007). A great diversity has been observed among yeasts for their parietal adsorption activity: the outermost layer of the cell wall has a chemical composition that varies notably from yeast to yeast, and adsorption is very strain dependent. In the $\mathrm{pH}$ range of wine, mannoproteins carry negative charges and, as a consequence, they may establish electrostatic and ionic interactions with the other components of the wine (Huwig et al., 2001; Caridi, 2006; Caridi, 2007).

The goal of our study was to find the potential of a Saccharomyces cerevisiae commercial yeast strain and a strain isolated from a

\footnotetext{
* Corresponding author:e-mail: peter.raspor@bf.uni-lj.si

Acknowledgments: This research was supported by the Slovenian Public Research Agency (Project NoJ4-0838).
} 
spontaneous fermentation to reduce the concentration of OTA added to a liquid synthetic medium, and to determine the influence of OTA at high concentrations on fermenting yeast strains.

\section{MATERIALS AND METHODS}

\section{Yeast strains}

The yeast strains used in this study were a commercially available S. cerevisiae Lalvin EC-1118 (Lallemand, Canada) (as active dry yeast) and the yeast strain S. cerevisiae ZIM 1927, previously isolated from a spontaneous fermentation of a cv. Malvasia grape must in 2001 and obtained from the culture collection of industrial microorganisms, University of Ljubljana, Slovenia. The first strain was rehydrated as described by the producer (Lallemand, Canada), and then cultured in the yeast extract-malt extract (YM) broth ( $0.3 \%$ yeast extract; $0.3 \%$ malt extract; $0.5 \%$ peptone; obtained from Biolife, Italy) and 18.0\% glucose (for microbiology, Merck, Germany) at $28^{\circ} \mathrm{C}$ for $24 \mathrm{~h}$, with rotary shaking at $190 \mathrm{rpm}$. The S. cerevisiae ZIM 1927 was a three-day-old culture, maintained on YPD agar (YPD Broth, Oxoid, England), and cultured in YM medium as described for Lalvin EC-1118.

\section{Cultivation and medium}

The alcoholic fermentations were carried out in anaerobic conditions, following the methodology used by Čuš and Raspor (2008). The cultivations were performed in liquid YM with $18.0 \%$ glucose at $\mathrm{pH} 6.37$, previously sterilised by membrane filtration $(0.20 \mu \mathrm{m}$, Sartorius, Germany). The medium, in a $300 \mathrm{ml}$ fermentor, contained i) $280 \mathrm{~mL}$ of YM (control) and ii) $280 \mathrm{~mL}$ of YM spiked with OTA (Sigma-Aldrich, USA). The concentrations of OTA in the media, determined at time 0 days (Table 1), were $3.48 \mathrm{ng} / \mathrm{mL}$ and $4.95 \mathrm{ng} / \mathrm{mL}$ for ZIM 1927 and Lalvin 1118-EC respectively. The fermentations were performed in duplicate.

\section{Culture conditions and sampling}

The inocula were prepared as described above and added directly to the fermentors, to give a final concentration of $1 * 10^{6} \mathrm{CFU} / \mathrm{mL}$ in the medium. The kinetics of fermentation were followed by $\mathrm{CO}_{2}$ release measurement (weight loss). The fermentations were carried out at $20^{\circ} \mathrm{C}$. The samplings for determination of the OTA concentration in the media were done at three stages: at time 0 , at the end of the fermentation (less than $2 \mathrm{~g} / \mathrm{L}$ of resting reducing sugars) and after seven days of contact with yeast biomass. After seven days of biomass-media contact, yeast biomass was also collected for OTA determination in the biomass and the fermented media. The latter were also analysed for volatile acidity and concentration of reducing sugars. Biomass was collected by centrifugation; three times at $11200 \mathrm{x}$ g for $10 \mathrm{~min}$ to remove supernatant.

\section{Biomass recovery for stationary test}

For the stationary test, the biomass produced during fermentations under anaerobic conditions (Čuš \& Raspor, 2008) in liquid YM, with $18.0 \%$ of glucose at $\mathrm{pH} 6.37$, was recovered by centrifugation (10 min, $11200 \mathrm{x} \mathrm{g}$ ) and washed three times (10 min, 11200 $\mathrm{x}$ g) with phosphate buffer ( $\mathrm{pH} 6.37$, sterilised by membrane filtration (0.20 $\mu \mathrm{m}$, Sartorius, Germany). Finally, the cells were resuspended in the phosphate buffer to give a final concentration of $0.44 \mathrm{~g} / \mathrm{mL}$.

\section{Stationary tests for biomass reduction of ochratoxin A}

The test was performed in two replicates in tubes containing $5 \mathrm{~mL}$ of assay solution, consisting of $4.890 \mathrm{~mL}$ of phosphate buffer ( $\mathrm{pH}$

\section{TABLE 1}

Removal of OTA in YM media (18.0\% glucose), pH 6.37 during stages of fermentation for S. cerevisiae yeast strains ZIM 1927 and Lalvin EC-1118 at $20^{\circ} \mathrm{C}$. Data reported are average values of two independent experiments carried out under identical conditions.

\begin{tabular}{lcc}
\hline Strain / fermentation stage & & \\
\hline Lalvin EC-1118 & $\begin{array}{c}\text { Concentration of OTA } \\
\text { in medium (ng/ml) }\end{array}$ & $\begin{array}{c}\text { \% OTA in } \\
\text { medium }\end{array}$ \\
\hline Start fermentation & $4.95^{\mathrm{a}}$ & 100.0 \\
End fermentation & $4.82^{\mathrm{a}}$ & 97.4 \\
7 days media-biomass contact & $3.69^{\mathrm{b}}$ & 74.6 \\
ZIM 1927 & & 100.0 \\
Start fermentation & $3.48^{\mathrm{c}}$ & 98.0 \\
End fermentation & $3.41^{\mathrm{c}}$ & 70.7 \\
7 days media-biomass contact & $2.46^{\mathrm{d}}$ & \\
\hline
\end{tabular}

Start fermentation $\mathrm{T}=0$ days.

End fermentation: $<2 \mathrm{~g} / \mathrm{L}$ glucose.

7 days after fermentation (daily mixing).

a,b,c : significant difference at $P \leq 0.05$.

6.37), with $0.010 \mathrm{~mL}$ of stock solution of OTA (Sigma-Aldrich, USA) added to give a final concentration of $5.00 \mathrm{ng} / \mathrm{mL}$ at $20^{\circ} \mathrm{C}$. To each tube, $0.1 \mathrm{ml}$ of a yeast biomass suspension (viable or non-viable cells) in phosphate buffer was added to give a final concentration of $0.044 \mathrm{~g} / \mathrm{mL}$. Non-viable cells were prepared by the addition of Na-azide (Sigma-Aldrich, USA) to biomass suspended in phosphate buffer $(0.025 \%$ final concentration in media) in order to exclude metabolic action and preserve the structural integrity of the cells (Bejaoui et al., 2004; Nunez et $a l ., 2007)$. After seven days of contact between the biomass and the media (Martínez-Rodriguez et al., 2001a,b; 2002; Nunez et al., 2007), with or without agitation (rotary shaking of tubes at $190 \mathrm{~min}^{-1}$ ), the solution was centrifuged and the non-adsorbed amounts of OTA in the medium were measured.

\section{Extraction of OTA from yeast biomass and YM media}

The extraction of OTA from yeast biomass and YM samples was performed using the organic extraction protocol for wine and grape samples, proposed by the manufacturer of the enzyme immunoassay kit used, I'screen Ochra (Tecna S.r.1., Trieste, Italy), which in our case was modified for $500 \mu \mathrm{L}$ sample volumes. Briefly, $100 \mathrm{mg}$ of sample wet biomass was first transferred in a $2 \mathrm{~mL}$ Eppendorf tube, washed two times with $1 \mathrm{~mL}$ of distilled water, centrifuged $(5 \mathrm{~min}, 1500 \mathrm{~g}$ ) and resuspended in $400 \mu \mathrm{L}$ of $\mathrm{H}_{2} \mathrm{O}$. In the case of YM media, $500 \mu \mathrm{L}$ of sample was collected in the tube without further treatment. To each sample, $500 \mu \mathrm{L}$ $1 \mathrm{M} \mathrm{HCl}$ and $1 \mathrm{~mL}$ of dichloromethane were added and mixed at $1200 \mathrm{rpm}$ in a rotary shaker (TTS2, IKA, USA) for $15 \mathrm{~min}$ at room temperature. This was followed by centrifugation at $2200 \mathrm{~g}$ for $15 \mathrm{~min}$. Then, $500 \mu \mathrm{L}$ of the lower dichlormethane phase was pipetted in another $2 \mathrm{~mL}$ Eppendorf tube and $250 \mu \mathrm{L}$ of $130 \mathrm{mM}$ $\mathrm{NaHCO}_{3}(\mathrm{pH} 8.1)$ was added. This was mixed again for $15 \mathrm{~min}$ at $1200 \mathrm{rpm}$. Finally, samples were centrifuged at $2200 \mathrm{~g}$ for 15 min, and $200 \mu \mathrm{L}$ of the upper polar phase was taken and analysed with the immunoassay kit. 
The yield of OTA extraction from yeast biomass, determined from a series of five independent extractions using $100 \mathrm{mg}$ cell biomass spiked with $25 \mathrm{ng}$ OTA, was $37.9 \pm 1.5 \%$.

\section{Determination of OTA residues}

The determination of OTA residues in the extracts of YM medium and cell biomass was performed with the commercial kit L'screen Ochhra (Tecna S.r.l., Trieste, Italy), following the manufacturer's protocol.

\section{Determination of reducing sugars and volatile acidity}

After the cultivation, the reducing sugars and the volatile acidity in the medium were determined according to the accredited methods in the Central Laboratory of the Agricultural Institute of Slovenia. Reducing sugars were determined according to the modified Rebelein method: $10 \mathrm{~mL}$ of the alkaline copper salt solution, $5 \mathrm{~mL}$ of Segnet salt and $2 \mathrm{~mL}$ of sample were placed in a $300 \mathrm{~mL}$ Erlenmeyer flask. The mixture was boiled for exactly 45 seconds. The flask was cooled down immediately and $5 \mathrm{~mL}$ of $30 \%$ potassium iodide solution, $5 \mathrm{~mL}$ of $16 \%$ sulphuric acid and $5 \mathrm{~mL}$ of starch solution $(10.0 \mathrm{~g} / \mathrm{L})$ were added. The mixture was titrated with $0.055 \mathrm{M}$ sodium thiosulphate solution (to a yellowcream colour). Blank titration was carried out, in which the 2.0 $\mathrm{mL}$ of sample was replaced with $2.0 \mathrm{~mL}$ of distilled water. The concentration of the reducing sugars in the sample was calculated according to the volume of sodium thiosulphate used in both titrations (EEC, 1990).

Volatile acidity was determined by titration of the distillate obtained by steam distillation. A total of $20 \mathrm{~mL}$ of sample, freed from carbon dioxide, was placed in the distillation flask and $0.5 \mathrm{~g}$ of tartaric acid was added. Distillation was done with steam distillation apparatus (Oenoextracteur Chenard). At least $250 \mathrm{~mL}$ of the distillate was collected. The distillate was titrated with $0.1 \mathrm{M}$ sodium hydroxide solution, using phenolphthalein as an indicator. The volatile acidity expressed in grams of acetic acid per litre was calculated according to the volume of sodium hydroxide used in the titration (EEC, 1990).

\section{Statistical analysis}

The analysed data were studied by one-way ANOVA (Microsoft Office Excel 2003, USA). The statistical level of significance was set at $P \leq 0.05$. The means were compared with the Tukey test (T-test).

\section{RESULTS AND DISCUSSION}

\section{OTA removal during alcoholic fermentation and yeast biomass contact}

Fermentation kinetics (Fig. 1), which were followed by the daily release of $\mathrm{CO}_{2}$ (weight loss), showed no significant differences between the controls and the fermentations with added OTA. After the completion of fermentation, the yeast biomass was maintained in contact with the media for seven days by daily mixing. During this time, the major proportion of mannose was released from the yeast cell walls into the media (Nunez et al., 2007) due to accelerated autolysis triggered by the lack of nutrients (MartínezRodriguez et al., 2001a; 2001b; 2002). However, during the alcoholic fermentation conducted by both yeast strains, no significant reduction was found in the concentration of OTA. The concentrations detected were $3.41 \mathrm{ng} / \mathrm{mL}$ and $4.82 \mathrm{ng} / \mathrm{mL}$, for ZIM 1927 and Lalvin EC-1118 respectively (Table 1). On the other hand, a significant reduction was observed after seven days of contact between the media and yeast biomass. The final concentrations detected in the media were $2.46 \mathrm{ng} / \mathrm{mL}$ and 3.69 ng/mL for ZIM 1927 and Lalvin EC-1118 respectively. Under the conditions used in our study, the two strains were unable to significantly reduce the concentration of OTA in synthetic media during the alcoholic fermentation phase. This result contrasts with that reported by Bejaui et al. (2004), who used different conditions that have been found to affect OTA removal potential: $\mathrm{pH}$, media and strains (Bejaoui et al., 2004; Caridi, 2006; 2007; Cecchini et al., 2006). In the post-fermentation period, 25.4\% (Lalvin EC1118 ) and $29.3 \%$ (ZIM 1927) reductions were achieved by the yeast strains. At the same time, although the initial concentration of OTA in the media was different for the two strains, the degree of removal induced by the two strains was not significantly different. These results suggest that the release of mannoproteins from cell walls after the completion of fermentation (Caridi, 2006; 2007; Nunez et al., 2007) is important in the removal of OTA.

\section{Concentration of OTA in wet yeast cell biomass}

To determine the OTA removal potential of yeast biomass in the growth assay, the yeast biomass was recovered from the medium after the extended medium-biomass contact period (seven days) and the cell-associated OTA concentration was determined. For the ZIM 1927 strain, $15.92 \mathrm{ng}$ OTA/100 mg of wet weight biomass was found, and $14.49 \mathrm{ng}$ OTA/100 mg of wet weight biomass for the Lalvin EC-1118 strain. In spite of the different origins of these two strains, no significant difference was detected in OTA removal capacity, which was unexpected in the light of other reports (Bejaoui et al., 2004; Caridi, 2006; 2007; Cecchini et al., 2006).

\section{OTA removal in yeast stationary phase biomass tests}

The yeast stationary phase assays were performed to compare the OTA removal potential of viable and non-viable yeast biomass, and to determine whether agitation during biomass-medium contact (rotary shaking of tubes at $190 \mathrm{~min}^{-1}$ ) affects the OTA removal as well. We tested fresh, washed biomass, in phosphate buffer ( $\mathrm{pH}$ 6.37), to ensure that other compounds present in the cultivation media did not affect the reduction of OTA. The $\mathrm{pH}$ was the same as in growth assays.

In the results of others researchers (Bejaoui et al., 2004; Moruno et al., 2005), the biomass concentration in the assay media is critical when determining OTA removal potential, and we therefore used the same concentration $(0.0088 \mathrm{~g} / \mathrm{mL})$ for both strains (media of wet weight biomass produced by the two yeasts in batch alcoholic fermentation carried out in YM medium with $18.0 \%$ glucose; results not shown). Independently of the adsorption assay type, significant removal of OTA was obtained (Table 2). The results show that, for both strains, there are no significant differences between viable and non-viable yeast biomass OTA removal when comparing within the same strain and the same treatment (agitated or not agitated) (Table 2). These results suggest strongly that OTA is not degraded by yeast metabolism and that adsorption of OTA is a likely mechanism to account for its reduction. As in the stationary stage of the growth assay, as well as in the stationary assays, the release of mannoproteins appeared to trigger OTA reduction (Nunez et al., 2007) in both viable and non-viable biomass. The strain ZIM 1927 reduced OTA the most in the case of dead biomass when agitation was applied - by $54.4 \%$. This was 
statistically significantly different compared to the trials with the strain ZIM 1927 viable and non-viable biomass when agitation was not applied, when only 21.0 and $21.4 \%$ removal respectively was obtained. The trend of a higher degree of OTA removal in agitated assays when compared to non-agitated assays of the same strain and viability is strongly present (Table 2). However, this is confirmed statistically only in ZIM1927 non-viable biomass assays. For strain Lalvin-1118-EC there were not statistically significant differences between the viable and non-viable yeast biomasses. Along with the confirmation that the mechanism of OTA removal by these two $S$. cerevisiae yeast strains involves adsorption, the extent of adsorption is perhaps lower than it

\section{TABLE 2}

Removal of OTA in phosphate buffer pH 6.37 in stationary tests, after treatments with different types of yeast cell biomass for seven days at $20^{\circ} \mathrm{C}$. Data reported are average values of two independent experiments carried out under identical conditions.

\begin{tabular}{lcc}
\hline $\begin{array}{l}\text { Treatment in phosphate buffer } \\
\mathbf{p H}=\mathbf{6 . 3 7}\end{array}$ & OTA ng/mL & \% of OTA \\
\hline ZIM1927 Non-viable cells & $3.93^{\mathrm{b}}$ & 78.6 \\
ZIM1927 Non-viable ( $\underline{\mathrm{R}})$ & $2.28^{\mathrm{c}}$ & 45.6 \\
ZIM1927 Viable cells & $3.95^{\mathrm{b}}$ & 79.0 \\
ZIM1927 Viable cells (ㅁ) & $3.10^{\mathrm{b}, \mathrm{c}}$ & 62.0 \\
EC-1118 Non-viable cells & $4.09^{\mathrm{b}}$ & 81.8 \\
EC-1118 Non-viable cells (R) & $3.64^{\mathrm{b}}$ & 72.8 \\
EC-1118 Viable cells & $4.33^{\mathrm{b}}$ & 86.6 \\
EC-1118 Viable cells $(\underline{\mathrm{R}})$ & $3.90^{\mathrm{b}}$ & 78.0 \\
\hline
\end{tabular}

Concentration of dead or live yeast biomass added in tubes was $0.0088 \mathrm{~g} / \mathrm{ml}$. Initial concentration of OTA (ochratoxin A) in media $5.00^{\mathrm{a}} \mathrm{ng} / \mathrm{mL}$.

R: Agitated: (rotary mixing of tubes at $190 \mathrm{~min}^{-1}$ ).

a,b,c: significant difference $P \leq 0.05$. might be at a lower pH (Bejaoui et al., 2004; Ringot et al., 2005). Adsorption is affected by $\mathrm{pH}$ because of different adsorption mechanisms used by different microorganisms, and because of cell wall composition (Huwig et al., 2001).

\section{Volatile acidity and reducing sugars}

The concentrations of volatile acids and reducing sugars were determined in the culture media after the seven-day period of media-biomass contact (Table 3). It can be seen that, for both strains, OTA addition to the media caused significantly higher production of volatile acidity. The concentrations produced in batch fermentations to which OTA was added initially were higher by 0.08 and $0.13 \mathrm{~g} / \mathrm{L}$ for the strains Lalvin EC-1118 and

\section{TABLE 3}

Concentration of reducing sugar after 29 days of alcoholic fermentations with OTA conducted in YM with 18.0\% glucose and pH 6.37 for the Saccharomyces cerevisiae strains ZIM 1927 and Lalvin EC-1118 at $20^{\circ} \mathrm{C}$. Data reported are average values of two independent experiments carried out under identical conditions.

\begin{tabular}{lcc}
\hline Sample & $\begin{array}{c}\text { Concentration of } \\
\text { reducing sugars }(\mathrm{g} / \mathrm{L})\end{array}$ & $\begin{array}{c}\text { Concentration of volatile } \\
\text { acidity }(\mathrm{g} / \mathrm{L})\end{array}$ \\
\hline EC-1118 & $1.50^{\mathrm{a}}$ & $0.45^{\mathrm{a}}$ \\
EC-1118 OTA & $1.00^{\mathrm{a}}$ & $0.53^{\mathrm{b}}$ \\
ZIM 1927 & $0.40^{\mathrm{b}}$ & $0.48^{\mathrm{a}}$ \\
ZIM 1927 OTA & $0.08^{\mathrm{c}}$ & $0.61^{\mathrm{c}}$ \\
\hline
\end{tabular}

Control (ZIM 1927, 1118EC), OTA was not added.

OTA was added to the medium (ZIM 1927 OTA, 1118 EC OTA).

a,b,c, significant difference at $P \leq 0.05$.

Mean values with the same letter in the same column do not differ significantly $P \leq 0.05$.

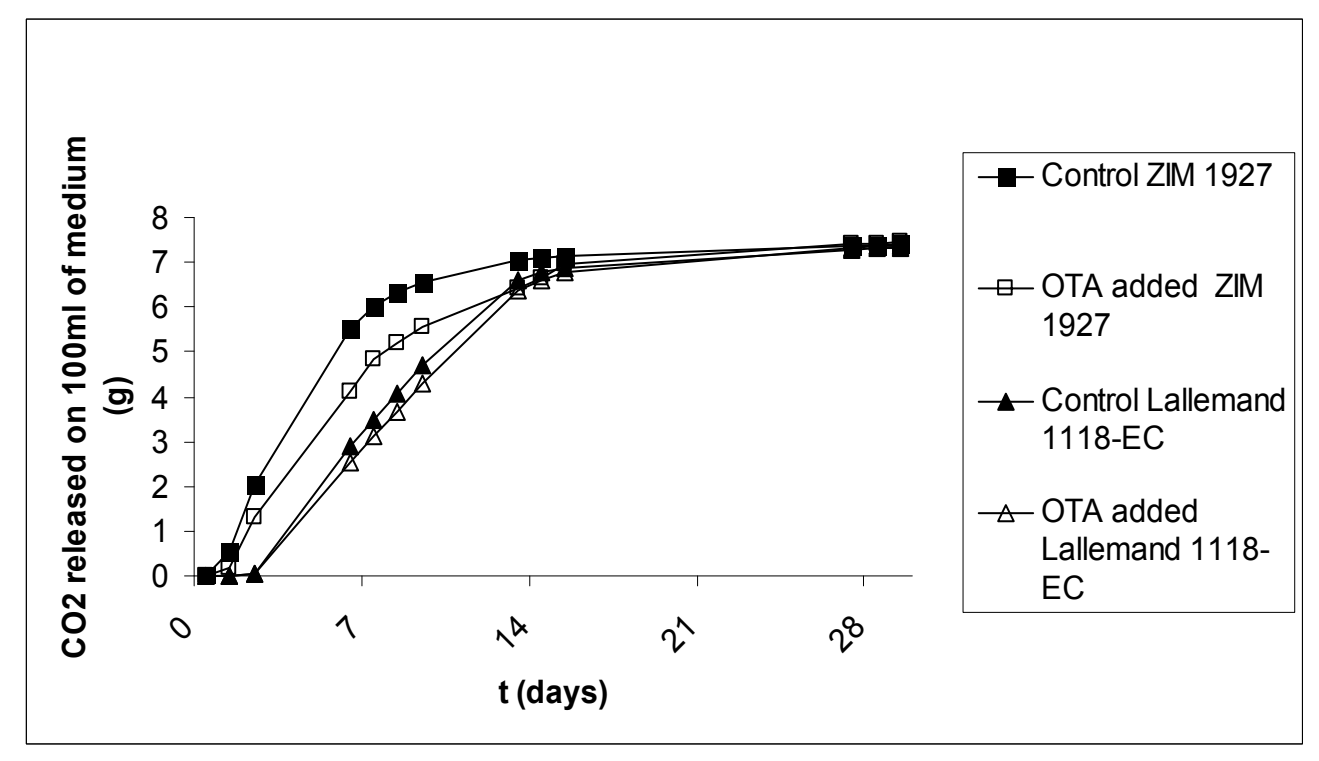

FIGURE 1

Growth of ZIM 1927 and Lalvin 1118EC (Lallemand) in YM medium (glucose: 18.0\%; pH 6,37; incubation at $20^{\circ} \mathrm{C}$ in semianaerobiosis) in the presence of OTA formulations; $4.95 \mathrm{ng} / \mathrm{mL}$ for Lalvin 1118-EC and $3.48 \mathrm{ng} / \mathrm{mL}$ for ZIM 1927 or in the absence of OTA (control). Data reported are average values of two independent experiments carried out under identical conditions. 
ZIM 1927 respectively, in comparison to fermentations where OTA was not added (controls). The production of volatile acidity was significantly higher for strain ZIM 1927, suggesting that this strain was more sensitive than Lalvin EC-1118 to the presence of OTA. This is also suggested by the fact that, even although the initial concentration of OTA added was higher for Lalvin EC1118 , by $1.47 \mathrm{ng} / \mathrm{mL}$ in comparison to ZIM 1927, the former is producing $0.08 \mathrm{~g} / \mathrm{L}$ less volatile acidity. These data show that the concentrations of OTA used in these experiments were sufficient to affect the production of volatile acidity by wine strains of $\mathrm{S}$. cerevisiae in synthetic media.

Contrary to the production of volatile acidity, OTA did not negatively affect the fermentation capacity of these yeast strains or, consequently, the concentration of reducing sugars in the media. Independently of OTA addition, Lalvin EC-1118 shows lower fermentation capacity in comparison to ZIM 1927, and there were no significant differences whether OTA was added to the former or not. On the other hand, the addition of OTA to fermentations with the ZIM 1927 strain resulted in a lower concentration of reducing sugars, and this was significantly lower $(0.08 \mathrm{~g} / \mathrm{L})$ in comparison to the concentration detected in the control fermentation $(0.40 \mathrm{~g} / \mathrm{L})$.

\section{CONCLUSIONS}

The aim of our study was to investigate the potential of viable and non-viable $S$. cerevisiae yeast biomass to reduce the concentration of OTA in synthetic media. The two genetically different wine yeast strains studied, Lalvin EC-1118, which is widely used commercially, and ZIM 1927, a laboratory strain previously isolated from a spontaneous fermentation of grape must, were able to significantly lower OTA concentrations in synthetic media. The evaluation of the adsorption capacity of yeast biomasses showed no significant differences between the commercial and wild strains tested. In our study we could not observe the removal of OTA during alcoholic fermentation, and significant removal of OTA was found only after the extended medium-biomass contact period (seven days), possibly as a consequence of yeast autolysis and the action of mannoproteins. Our results demonstrate that non-viable yeast cells, that is cells that are inactivated by an agent that does not affect cell wall integrity (in contrast to heat or acid treatment), do not show significantly different potential to remove OTA when compared to viable yeast cells in the stationary phase. These results suggest that OTA is not metabolised by the yeast. Moreover, this indicates that removal only involves adsorption processes mediated by yeast constituents.

Finally, the presence of OTA in synthetic media was found to influence fermentation capacity and the production of volatile acidity, which indicates that OTA can influence selected metabolic processes in synthetic media.

Further work will be needed to demonstrate that yeasts interact similarly with OTA in grape must.

\section{LITERATURE CITED}

Bejaoui H., Mathieu, F., Taillandier, P. \& Lebrihi, A., 2004. Ochratoxin A removal in synthetic and natural grape juices by selected oenological Saccharomyces strains. J. Appl. Microbiol. 97, 1038-1044.

Caridi A., 2006. Enological functions of parietal yeast mannoproteins. Antonie van Leeuwenhoek 82, 417-422.
Caridi A., 2007. New perspectives in safety and quality enhancement of wine through selection of yeasts based on the parietal adsorption activity. Int. J. Food Microbiol. 120, 167-172.

Cecchini F., Morassut, M., Moruno, E.G. \& Di Stefano, R., 2006. Influence of yeast strain on ochratoxin A content during fermentation of white and red must. Food Microbiol. 23, 411-417.

Chulze S.N., Magnoli, C.E. \& Dalcero, A.M., 2006. Occurrence of ochratoxin $\mathrm{A}$ in wine and ochratoxigenic mycoflora in grapes and dried vine fruits in South America. Int. J. Food Microbiol. 111, S5S9.

$\breve{C}$ uš F. \& Raspor, P., 2008. The effect of pyrimethanil on the growth of wine yeasts. Letts Appl. Microbiol. 47, 54-59.

EC, 2005. Commission Regulation (EC) No 123/2005 of 26 January 2005, amending Regulation (EC) No 466/2001 as regards ochratoxin A. European Commission. pp. $3-5$.

EEC, 1990. Commission Regulation Determining Community Methods for the Analysis of Wines ed.: Commission of the European Communities.

Fernandes A., Ratola, N., Cerdeira, A., Alves, A. \& Venancio, A., 2007. Changes in ochratoxin A concentration during winemaking. Am. J. Enol. Vitic. 58, 92-96.

Gambuti A., Strollo, D., Genovese, A., Ugliano, M., Ritieni, A. \& Moio, L., 2005. Influence of enological practices on ochratoxin A concentration in wine. Am. J. Enol. Vitic. 56, 155-162.

Hocking A.D., Leong, L.S., Kazi, A.B., Emmett, R.W. \& Scott, E.S., 2007. Fungi and mycotoxins in vineyards and grape products. Int. J. Food Microbiol. 119, 8488 .

Huwig A., Freimund, S., Kapelli, O. \& Dutler, H., 2001. Mycotoxin detoxification of animal feed by different adsorbents. Toxicol. Letts 122, 179-188.

Leong L.S., Hocking, A.D., Varelis, P., Giannikopoulos, G. \& Scott, E.S., 2006. Fate of ochratoxin A during vinification of Semillon and Shiraz grapes. J. Agric. Food Chem. 54, 6460-6464.

Lo Curto R., Pellicano, T., Vilasia, F., Munafo, P. \& Dugoa, G., 2004. Ochratoxin A occurrence in experimental wines in relationship with different pesticide treatments on grapes. Food Chem. 84, 71-75.

Marquardt, R.R. \& Frohlich, A.A., 1992. Review of recent advances in understanding ochratoxicosis. J. Anim. Sci. 70, 3968-3988.

Martínez-Rodriguez, A.J., Carrascosa, A.V. \& Polo, M.C., 2001a. Release of nitrogen compounds to the extracellular medium by three strains of Saccharomyces cerevisiae during induced autolysis in a model wine system. Int. J. Food Microbiol. $68,155-160$.

Martínez-Rodríguez, A.J., Polo, M.C. \& Carrascosa, A.V., 2001b. Structural and ultrastructural changes in yeast cells during autolysis in a model wine system and in sparkling wines. Int. J. Food Microbiol. 71, 45-51.

Martınez-Rodrıguez, A.J., Carrascosa,A.V., Martın-Alvarez, P.J., Moreno-Arribas, V. \& Polo, M.C., 2002. Influence of the yeast strain on the changes of the amino acids, peptides and proteins during sparkling wine production by the traditional method. J. Ind. Microbiol. Biotechnol. 29, 314-322.

Mateo R., Medina, A., Mateo, E.M., Mateo, F. \& Jiménez, M., 2007. An overview of ochratoxin A in beer and wine. Int. J. Food Microbiol. 119, 79-83.

Moruno E.G., Sanlorenzo, C., Boccaccino, B. \& Di Stefano, R., 2005. Treatment with yeast to reduce the concentration of ochratoxin A in red wine. Am. J. Enol. Vitic. 56, 73-76.

Nunez, P.Y., Pueyo, E., Carrascosa, A.V. \& Martinez-Rodriguez, A.J., 2007. Effects of aging and heat treatment on whole yeast cells and yeast cell walls and on adsorption of ochratoxin A in a wine model system. J. Food Protection 71, 1496-1499.

Ratola N., Abade, E., Simoes, T., Venancio, A. \& Alves, A., 2005. Evolution of ochratoxin A content from must to wine in port wine microvinification. Annals Bioanal. Chem. 382, 405-411.

Ringot D., Lerzy, B., Bonhoure, J.P., Auclair, E., Oriol, E. \& Larondelle, Y., 2005. Effect of temperature on in vitro ochratoxin A biosorption onto yeast cell wall derivatives. Process Biochem. 40, 3008-3016.

Zimmerli B. \& Dick, R., 1996. Ochratoxin A in table wine and grape juice: occurrence and risk assessment. Food Additives and Contaminants 13, 655-668. 